\title{
KAPASITAS GESER - LENTUR BALOK BETON BERTULANG HIGH VOLUME FLY ASH SELF COMPACTING CONCRETE (HVFA-SCC) DENGAN KADAR FLY ASH 60\% DAN BALOK BETON BERTULANG NORMAL
}

\author{
Agus Setiya Budi ${ }^{1)}$, Endah Safitri ${ }^{2)}$, Sheilla Shelina ${ }^{3)}$ \\ ${ }^{1), 2)}$ Dosen Program Studi Teknik Sipil, Fakultas Teknik, Universitas Sebelas Maret \\ ${ }^{3)}$ Mahasiswa Prodi Teknik Sipil, Fakultas Teknik, Universitas Sebelas Maret \\ J1. Ir. Sutami 36A, Kentingan Surakarta 57126; Telp 0271-634524. \\ Email: asb.asb09@yahoo.co.id ${ }^{1}$,,$\underline{\text { safitri47@gmail.com²) }}$, $\underline{\text { sheillashelina99@gmail.com } 3 \text { (3) }}$
}

\begin{abstract}
The development of the construction world requires that construction work effectively with maximum results. High Volume Fly Ash Self Compacting Concrete (HVFA-SCC) is an innovation that has many advantages including high workability and classified as environmentally friendly concrete because it uses high levels of fly ash as a substitute for cement. Based on these innovations, the research to be carried out is to examine the flexural shear capacity of HVFA-SCC (High Volume Fly Ash Self Compacting Concrete) reinforced concrete beam with 60\% of fly ash content and normal reinforced concrete beam. The beam test is carried out at 28 days of concrete and the beams are tested using a loading frame testing tool and installing the LVDT and dial gange at the midpoint of the span and the point of loading. The results of beam test are values of maximum load, maximum deflection, and crack pattern of the beams. Based on this research, HVFA-SCC 60\% beam shear strength is $25.83 \mathrm{kN}$ with a normalized value of $1.16 \mathrm{kN} / \mathrm{MPa}$, higher than the normal shear force of $25.08 \mathrm{kN}$ with a normalized value of $0.85 \mathrm{kN} / \mathrm{MPa}$.
\end{abstract}

Keywords: Flexure - shear capacity, Fly ash, HVFA-SCC

\begin{abstract}
Abstrak
Perkembangan dunia konstruksi menuntut pembangunan agar bekerja efektif dengan hasil yang maksimal. High Volume Fly Ash Self Compacting Concrete (HVFA-SCC) merupakan sebuah inovasi yang memiliki banyak keunggulan diantaranya memiliki workability yang tinggi dan termasuk beton ramah lingkungan sebab menggunakan kadar fly ash yang tinggi sebagai pengganti semen. Berdasarkan inovasi tersebut, penelitian ini akan mengkaji kapasitas geser-lentur balok beton bertulang HVFA - SCC dengan kadar fly ash 60\% dan balok bertulang beton normal. Pengujian balok menggunakan loading frame yang dilakukan pada umur beton 28 hari. Balok diberi dial gauge pada titik pembebanan dan tengah bentang. Pengujian ini menghasilkan nilai beban maksimum, lendutan maksimum, dan pola retak pada balok. Nilai kapasitas geser untuk balok HVFA -SCC $60 \%$ adalah 25,83 $\mathrm{kN}$ dengan nilai normalisasi 1,16 kN/MPa, lebih besar daripada kapasitas geser balok beton normal 25,08 kN dengan nilai normalisasi $0,85 \mathrm{kN} / \mathrm{MPa}$.
\end{abstract}

Kata kunci: Fly ash, HVFA - SCC, Kapasitas geser - lentur

\section{PENDAHULUAN}

Kebutuhan dan tuntutan dalam pembangunan infrastruktur Indonesia semakin meningkat setiap waktu. Untuk mencapai efektifitas yang baik diperlukan banyak pembaharuan dari segi material maupun metode pelaksanaan. Beton yang memiliki tingkat workability tinggi akan meningkatkan efektifitas pengerjaan. Self Compacting Concrete ( SCC ) merupakan beton memadat mandiri yang dapat mengalir sendiri mengisi bekisting tanpa diperlukannya alat penggetar, sehingga bias dikatakan bahwa SCC memiliki tingkat workability tinggi. Bahan pembuat beton bukanlah bahan yang bersifat sustaianable terutama semen. Semen portland terbuat dari kombinasi bahan berkapur dimana bahan alam tersebut dapat habis jika digunakan dan di eksploitasi secara terus menerus. Proses produksi semen juga dapat menghasilkan pencemaran lingkungan. Maka dari itu kita membutuhkan bahan lain yang dapat menggantikan fungsi semen pada beton. High Volume Fly Ash (HVFA) Concrete adalah suatu inovasi beton dimana penggunaan semen digantikan oleh fly ash dengan kadar yang tinggi. Untuk meningkatkan efektifitas dari beton, Self-Compacting Concrete (SCC) dapat digabungkan dengan High Volume Fly Ash (HVFA) Concrete menjadi HVFASCC.

\section{METODE PENELITIAN}

Pada penelitian ini akan menguji balok HVFA-SCC pada umur beton 28 hari, untuk mengetahui perilaku geser lentur dari balok yang kemudian dibandingkan dengan perilaku balok beton normal. Pada penelitian akan digunakan benda uji balok beton bertulang yang terdiri dari 3 buah balok HVFA-SCC $60 \%$ dan 3 buah balok beton konvensional dengan ukuran balok masing - masing $10 \mathrm{~cm}$ x 18,5 cm x 130 cm (lebar x tinggi x panjang). Benda uji diilustrasikan seperti pada Gambar 1. 


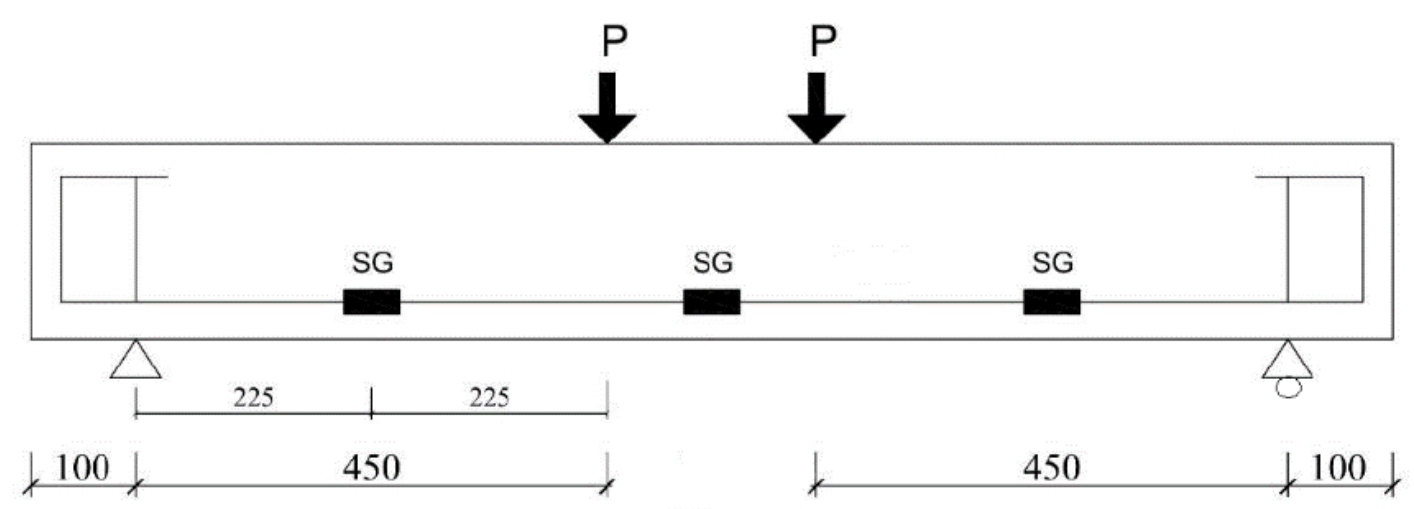

Gambar 1. Balok HVFA-SCC dan normal

Set Up alat pengujian ditunjukkan pada Gambar 2.

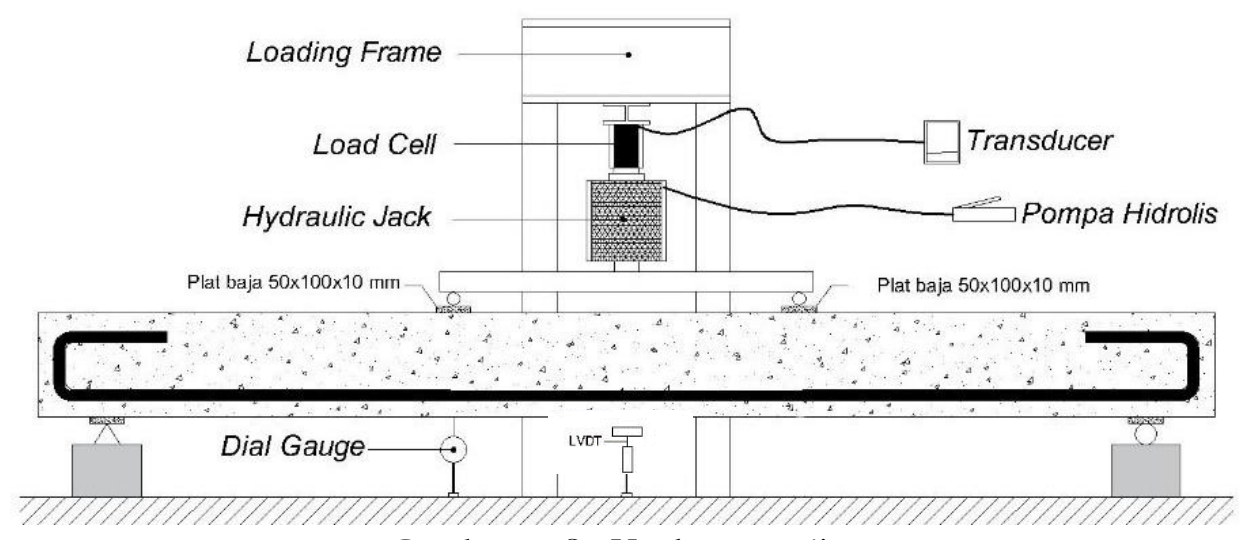

Gambar 2. Set Up alat pengujian

\section{High Volume Fly Ash - Self Compacting Concrete (HVFA - SCC)}

HVFA-SCC merupakan beton dengan kadar fly ash yang tinggi sebagai substitusi semen dan memiliki kriteria SCC. HVFA-SCC memiliki keungguluan gabungan dari HVFAC dan SCC. Self-compacting concrete (SCC) memiliki tiga persyaratan fungsional, yaitu kemampuan mengisi celah, kemampuan lolos, dan ketahanan terhadap segregasi. Karakteristik tersebut akan beerdampak pada waktu pengerjaan, biaya tenaga kerja, , dan lingkungan kerja yang lebih baik dengan menghilangkan dampak getaran. HVFAC merupakan beton dengan penggunaan fly ash dengan presentase yang tinggi sebagai substitusi penggunaan semen. Penggunaan HVFAC dapat memberikan dampak positif pada lingkungan sebab fly ash merupakan limbah berbahaya yang perlu dikelola dengan baik sehingga tidak menimbulkan pencemaran lingkungan. $\mathrm{Ca}(\mathrm{OH})_{2}$ dapat diikat oleh $\mathrm{SiO}_{2}$, yang dimiliki oleh fly ash, menjadi C-S-H yang dibutuhkan sebagai bahan perekat beton. Reaksi tersebut akan berdampak pada mutu dan durabilitas beton.

\section{Kapasitas Geser Balok}

Balok tanpa tulangan geser memiliki kekuatan geser yang dipengaruhi oleh compression zone $\left(\mathrm{V}_{\mathrm{cz}}\right)$, interlock of aggregate $\left(\mathrm{V}_{\mathrm{a}}\right)$, dan dowel action $\left(\mathrm{V}_{\mathrm{d}}\right)$. Balok pada penelitian ini merupakan balok tanpa tulangan geser, sehingga kekuatan geser sepenuhnya berasal dari kuat geser beton $\left(\mathrm{V}_{c}\right)$.

$$
\begin{gathered}
V_{u} \leq \phi V_{n} \\
V_{n}=V_{s}+V_{c} \\
V_{s}=0, \text { sehingga } V_{n}=V_{c}
\end{gathered}
$$

Untuk menghitung $V_{c}$ dapat digunakan persamaan dari (Badan Standarisasi Nasional, 2019) dan (ACI 318-14, 2014), yaitu:

$$
V_{c}=0,17 \lambda \sqrt{f^{\prime}} c b u d
$$

$\mathrm{V}_{\mathrm{c}}$ juga dapat dihitung menggunakan persamaan (Niwa et al, 1986): 


\section{HASIL PENELITIAN DAN PEMBAHASAN}

\section{Hasil Pengujian Material}

Hasil pengujian material pasir ditampilkan dalam Tabel 1.

Tabel 1. Hasil uji agregat halus

\begin{tabular}{lccc}
\hline \multicolumn{1}{c}{ Jenis Uji } & Hasil & Standar & Keterangan \\
\hline Kadar Zat Organik & Kuning Muda & Kuning Muda & Memenuhi \\
Kadar Lumpur & $0,5 \%$ & Maksimal $5 \%$ & Memenuhi \\
Spesific Gravity & $2,475 \mathrm{gr} / \mathrm{cm}^{3}$ & $2,5-2.7 \mathrm{gr} / \mathrm{cm}^{3}$ & Memenuhi \\
\hline
\end{tabular}

Hasil uji agregat kasar ditampilkan dalam Tabel 2.

Tabel 2. Hasil pengujian agregat

\begin{tabular}{lccc}
\hline \multicolumn{1}{c}{ Jenis Uji } & Hasil & Standar & Keterangan \\
\hline Spesific Gravity & $2,718 \mathrm{gr} / \mathrm{cm}^{3}$ & $2,5-2,7 \mathrm{gr} / \mathrm{cm}^{3}$ & Memenuhi \\
Keausan Agregat & $26,90 \%$ & $<50 \%$ & Memenuhi \\
\hline
\end{tabular}

Baja yang digunakan memiliki panjang $30 \mathrm{~cm}$ dan berdiameter $16 \mathrm{~mm}$ yang dibubut sepanjang Lo $6,5 \mathrm{~cm}$ dan diameter setelah dibubut $14 \mathrm{~mm}$. Hasil pengujian baja ditampilkan pada Tabel 3.

Tabel 3. Hasil pengujian baja

\begin{tabular}{cccccc}
\hline $\mathbf{D}(\mathbf{m m})$ & $\mathbf{A}_{\mathbf{s}}\left(\mathbf{m m}^{2}\right)$ & $\mathbf{P}_{\text {leleh }}(\mathbf{N})$ & $\mathbf{P}_{\text {maks }}(\mathbf{N})$ & $\left.\mathbf{F}_{\mathbf{y}} \mathbf{( M P a}\right)$ & $\left.\mathbf{F}_{\mathrm{u}} \mathbf{( M P a}\right)$ \\
\hline 16 & 158,37 & 72 & 98,24 & 455 & 620 \\
\hline
\end{tabular}

\section{Hasil Pengujian Beton Segar}

Beton segar HVFA-SCC diukur nilai Slump Flow, T50, L-Box, dan V-Funnel nya. Beton segar NC diukur nilai slump nya.

Tabel 4. Hasil Pengujian Slump Flow dan $\mathrm{T}_{50}$ HVFA-SCC 60\%

\begin{tabular}{|c|c|c|c|c|c|c|c|}
\hline \multirow{3}{*}{ Kode } & \multicolumn{4}{|c|}{ Pengujian Slump Flow dan $\mathrm{T}_{50}$} & \multirow{2}{*}{\multicolumn{3}{|c|}{$\begin{array}{l}\text { Syarat menurut } \\
\text { EFNARC }\end{array}$}} \\
\hline & \multicolumn{3}{|c|}{ Diameter } & \multirow{2}{*}{$\begin{array}{c}\text { Waktu } \\
t_{50} \\
(\mathrm{dt}) \\
\end{array}$} & & & \\
\hline & $\begin{array}{c}\mathrm{d} 1 \\
(\mathrm{~mm})\end{array}$ & $\begin{array}{c}\mathrm{d} 2 \\
(\mathrm{~mm})\end{array}$ & $\begin{array}{c}d_{\text {rata-rata }} \\
(\mathrm{mm})\end{array}$ & & $\begin{array}{l}T_{50} \\
(s)\end{array}$ & $\begin{array}{l}d_{\text {rata-rata }} \\
(\mathrm{mm})\end{array}$ & Keterangan \\
\hline HVFA $60 \%$ & 580 & 600 & 590 & 3,16 & $2-5$ & $550-850$ & Memenuhi \\
\hline
\end{tabular}

Table 5. Hasil Pengujian L-Box HVFA-SCC 60\%

\begin{tabular}{cccccc}
\hline \multirow{2}{*}{ Kode } & \multicolumn{5}{c}{ L-Box Type } \\
\cline { 2 - 6 } & $\begin{array}{c}\mathbf{h}_{1} \\
(\mathbf{m m})\end{array}$ & $\begin{array}{c}\mathbf{h}_{2} \\
(\mathbf{m m})\end{array}$ & $\mathbf{h}_{2} / \mathbf{h}_{1}$ & $\begin{array}{c}\text { Syarat } \\
\left(\mathbf{h}_{2} / \mathbf{h}_{\mathbf{1}}\right)\end{array}$ & Keterangan \\
\hline HVFA 60\% & 100 & 95 & 0,95 & $0,8-1,0$ & Memenuhi \\
\hline
\end{tabular}

Tabel 6. Hasil Pengujian V-Funnel HVFA-SCC 60\%

\begin{tabular}{cccc}
\hline Kode & T (dt) & \multicolumn{2}{c}{ Klasifikasi menurut EFNARC } \\
\hline HVFA $60 \%$ & 5 & VS $1 \leq 8 \mathrm{dt}$ & VS $2=9-25 \mathrm{dt}$ \\
\hline
\end{tabular}

Pengujian beton segar HVFA-SCC 60\% menunjukkan bahwa beton memenuhi persyaratan self compacting concrete berdasarkan EFNARC. Hasil pengujian slump pada beton normal adalah $8 \mathrm{~cm}$, dimana nilai slump memenuhi persyaratan SNI 7656-2012. 


\section{Respon Lendutan Balok terhadap Beban}

Balok HVFA-SCC 60\% dan balok normal mengalami kegagalan geser-lentur dimana balok mengalami retak halus pada awal pembebanan yang dilanjutkan retak geser sebagai retak primer penyebab keruntuhan balok. Lendutan yang terjadi pada balok didapatkan melalui pembacaan dial gange setiap interval pembebanan $0,25 \mathrm{kN}$. Hubungan antara beban dan lendutan akan ditampilkan dalam bentuk grafik pada gambar 3 dan gambar 4.

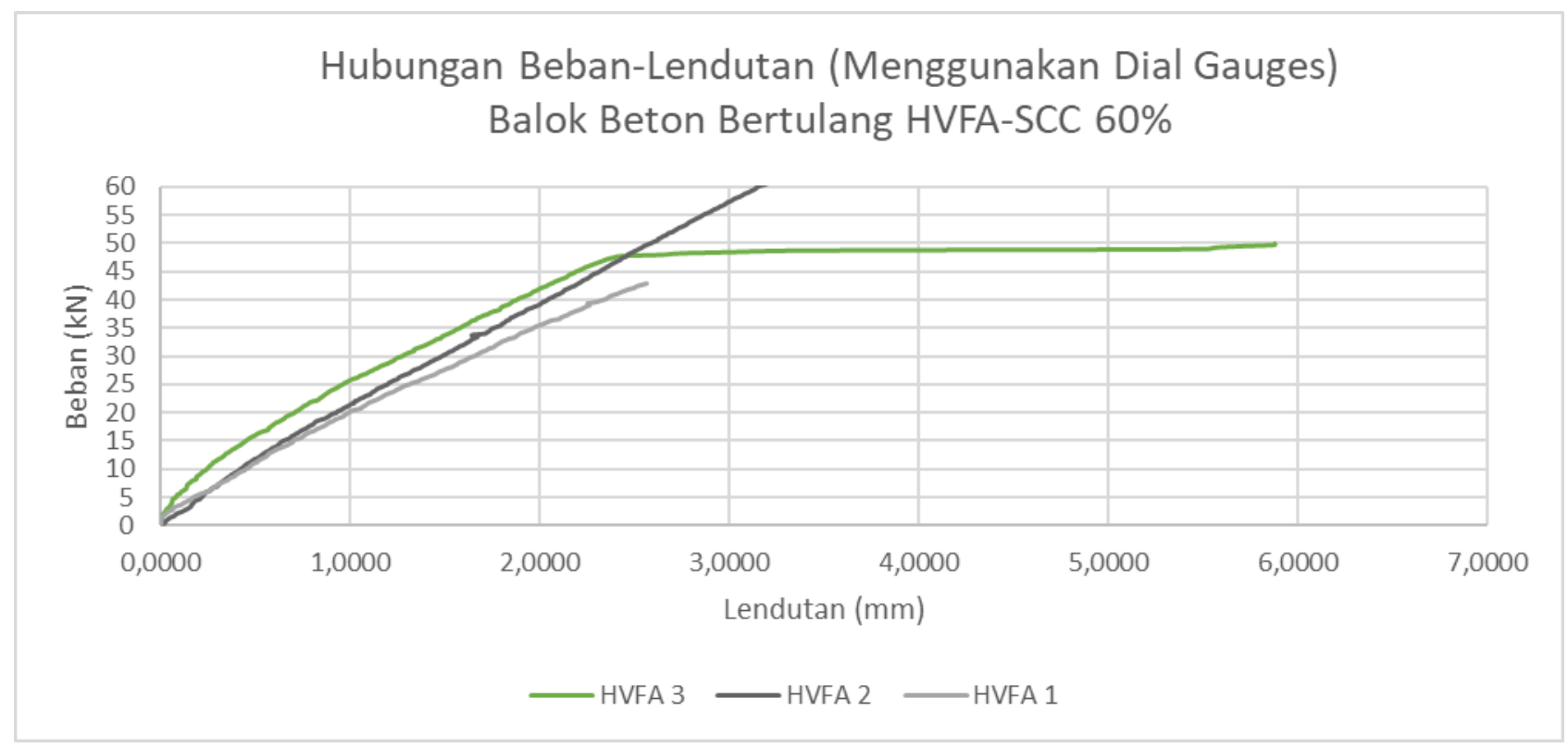

Gambar 3. Hubungan antara beban dan defleksi balok HVFA-SCC 60\%

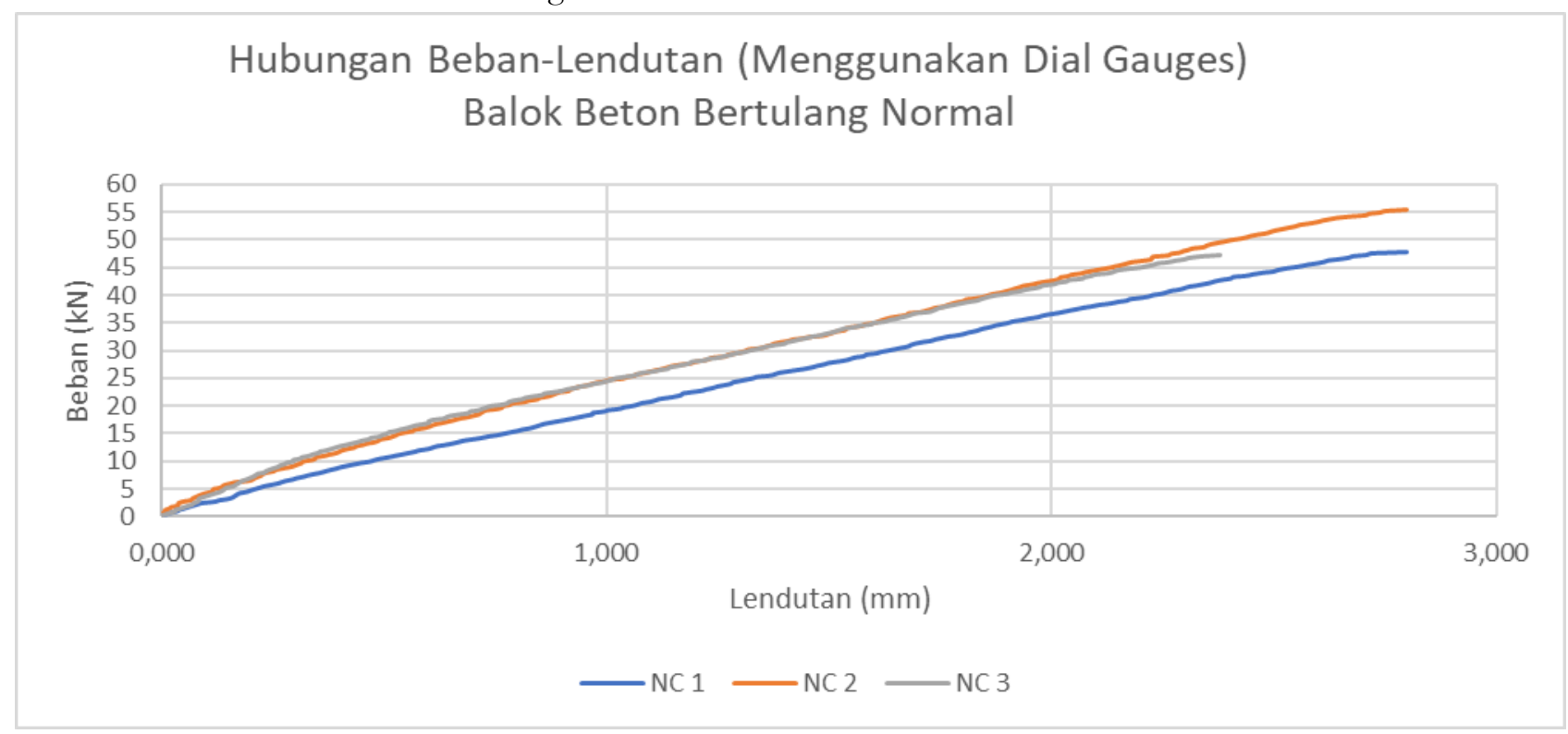

Gambar 4. Hubungan antara beban dan defleksi balok normal

Berdasarkan gambar 3 dan gambar 4, balok HVFA-SCC 60\% memiliki lendutkan maksimum sebesar 3,32 mm dengan beban $62,25 \mathrm{kN}$ dan balok beton normal memiliki lendutkan maksimum sebesar 2,79 mm dengan beban $55,50 \mathrm{kN}$.

\section{KESIMPULAN}

Berdasarkan hasil pengujian didapatkan nilai lendutan maksimum pada balok beton bertulang HVFA-SCC 60\% sebesar 3,32 $\mathrm{mm}$ pada beban $62,25 \mathrm{kN}$ lebih besar dari beton normal yang memiliki nilai lendutan maksimum sebesar $2,79 \mathrm{~mm}$ pada beban $55,50 \mathrm{kN}$. 


\section{UCAPAN TERIMAKASIH}

Vol 8, No 3 (2020): September

Penulis mengucapkan terima kasih kepada dosen pembimbing yang telah membagi ilmu dan waktu hingga penelitian ini terselesaikan. Terima kasih kepada tim beton tjap orangtua selaku tim kerja yang telah bekerja keras dalam penelitian ini.

\section{REFERENSI}

American Concrete Institute, 2014, “ACI 318-14: Building Code Requirements for Structural Concrete” Vol. 11.

Badan Standarisasi Nasional, 2019, "SNI 03-2847-2019 : Persyaratan Beton Struktural Untuk Bangunan Gedung dan Penjelasan Sebagai Revisi dari Standar Nasional Indonesia 2847 : 2013", Badan Standarisasi Nasional.

Badan Standarisasi Nasional, 2012, "SNI-7656: Tata Cara Pemilihan Campuran Untuk Beton Normal , Beton Berat dan Beton Mass".

EFNARC, 2005, "The European Guidelines for Self-Compacting Concrete”, The European Guidelines for Self Compacting Concrete, (May), 63. Retrieved from http://www.efnarc.org/pdf/SCCGuidelinesMay2005.pdf

Nawy, E. G., 1985, "Flexural Cracking Behavior of Pretensioned and Post-Tensioned Beams: The State of the Art", Journal Proceedings. Vol. 82 No. 6, pp. 890-900.

Niwa, J., Yamada, K., Yokozawa, K., \& Okamura, H., 1986, "Revaluation df The Equation for Shear Strength ff Reinforced Concrete Beams Without Web Reinforcement”, Doboku Gakkai Ronbunshu. Vol. 1986 No. 372, pp. 167-176. 